\title{
THE RELATIONSHIP BETWEEN GENETIC, NUCLEAR AND SOCIAL SEX
}

\author{
William M. Davidson, M.D., and Shirley Winn, B.Sc. \\ Department of Clinical Pathology, King's College Hospital and Medical School
}

\section{Introduction}

Reinvigorating processes play an essential part in all animal life. The frequently repeated periods of sleep allow for the restoration of cellular activities. The division of stem cells and the subsequent subdivision of a succession of operational daughter cells, with a relatively short life span, maintain tissues subject to wear and tear such as the blood and the skin. The main rejuvenating process, however, is sexual reproduction, which keeps alive the species by providing a new life span.

\section{Sexual Reproduction and Sexual Development}

The essence of sexual reproduction is the regrouping of the chromosomes with their constituent elements, the genes, to ensure a kaleidoscopic mixing of the hereditary factors and at the same time provide the opportunity for mutations to express themselves. This process, which somehow builds up a new store of vital energy, is of such fundamental importance to the race that it is not surprising so many of the genes have a bearing on it and that two of the 46 chromosomes are earmarked as sex chromosomes. These genetic factors are devoted to providing the physical conditions necessary for sexual reproduction; the development of the germinal cells leading to the haploid phase of life in the gametes; the sexual union with the resulting restoration of the diploid structure in the zygote; and the subsequent guarding and nourishing of the developing embryo. They also prepare the mental attitude to mating and ultimately mould the social behaviour of the community.

To achieve reproduction there has been a specialisation of development in the higher animals into the male, begetting and the female, conceiving and nurturing, partners. Basically this difference is determined by the genes, with a balance between those tending to maleness scattered on the autosomes and those with a female influence concentrated on the sex chromosomes
(Bridges, I921). The genes themselves are thoughto to be molecules of deoxyribonucleic acid, with their purine and pyrimidine residues arranged inf conformity with the inherited pattern to provides the template for the formation of ribonucleics acid. This in turn determines the structure of the various specialized proteins, including the stromar proteins, the enzymes and the organizers and these form the tissues and devise their secretions; including the steroid hormones from the endo- -1 crine organs. The sex pattern is thus passed tog every tissue, directing the nervous system, the endocrine organs, the gonads and the genifgits tract to the all-important task of producing youn

Normally the balance between the autosomes? and the sex chromosomes is such that if the are paired, the cortex of the gonadal blasteris develops into an ovary and any remnant of $\vec{i}$ eeco medulla is suppressed. The subsequent different tion of the female genital tract appears to be neutral development, for as Jost (1947) has shown early removal of the gonad in either sex leads to prominence of the paramesonephric (Müllerian) and suppression of the mesonephric (Wolffian) $D$ duct derivatives and the corresponding female type of development of the urogenital sinus. Or? the other hand if the sex chromosomes are unlike, that is XY, the cortex of the gonad is sup pressed, the medulla develops to a testis and the subsequent differentiation of the urogenital tract is in accordance with the male pattern. This:appears to be a positive action, and can be simu lated, at least to some extent, by the administration of androgens to the mother during thes critical period of development. Later, with puberty, hormonal influences differentiate the secondary characteristics in the two sexes. Malo formations may arise from some basic upset to the process of development or result from local distortion of growth and may be sufficiently sever@ to make the recognition of the anatomical sexw difficult or even impossible.

Usually the psychological outlook towards sex is in harmony with the chromosomes, the gonads and the external genitalia, but it may be at variances? 


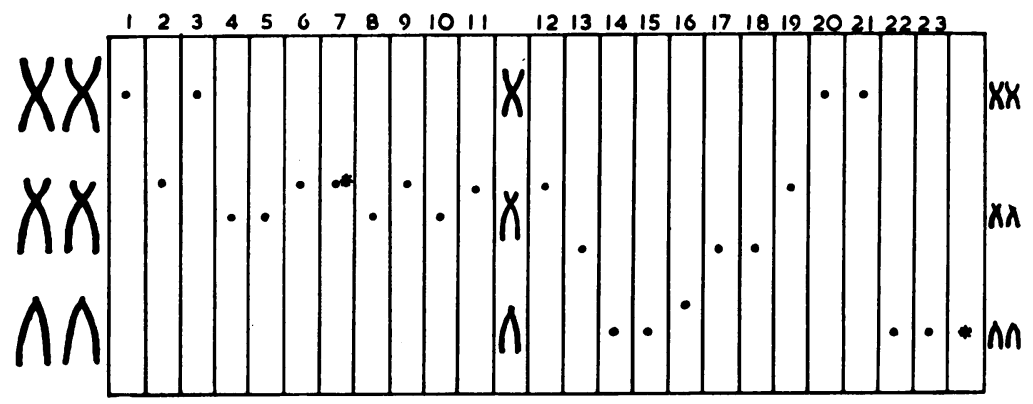

Fig. I.-Chromosomal sex in man. The chromosomes, arrested at the stage of diakinesis, arranged in order of size and whether the chromatid junction is central, subterminal, or terminal. The asterisks mark the position of the large $\mathrm{X}$ and the small $\mathrm{Y}$ chromosomes.

with them, particularly when some change in the genitalia has resulted in the child being reared as if of the opposite sex.

Thus we can consider the sex of an individual from the fundamental aspect of the genetic constitution; from the first visible differentiation in the chromosomal grouping; from the gonadal structure; from the anatomy of the external genitalia and the secondary sex characteristics; and from the mental outlook.

\section{The Genes and Chromosomes in Relation to Sex}

At the present time we cannot examine the genes directly and can only deduce their presence or absence from their actions and from family studies. The chromosomes have been subjected to direct examination for over fifty years, but it is only in the last decade that improvements in technique have made this a method of practical application. As long ago as 1924 Painter established that the sex chromosomes in man were $\mathrm{XX}$ in the female and XY in the male, but he had only poor preparations and believed there were 48 chromosomes in all. It was not until 1956 that Tjio and Levan and Ford and Hamerton establised that there are only 46 chromosomes. The new technique consists of culturing the bone marrow, or skin, to encourage the cells to enter the phase of mitotic division. When it is believed that a considerable number of cells are reaching this phase colchicine is added to block the mitoses in the stage of diakinesis, where the chromosomes have just split longitudinally, but the chromatids have not separated completely. The chromosomes, stained by the Feulgen method, are then sufficiently spread out by pressure, to allow each one to be distinguished (Ford et al., 1958).

From experience of the new method and using such criteria as the size and the position of the attachment of the chromatids (Fig. I) it has been possible to establish with fair certainty the identity of at least a dozen of the chromosome pairs and less definitely the remaining eleven, including the XX pair (Ford et al., I959 a and b). The $\mathrm{X}$ chromosomes are probably about the seventh pair and are metacentric, that is, with the chromatids attached centrally, for in the male there is an odd chromosome of about this size and form. Four of the chromosomes in the female and five, including the $\mathrm{Y}$, in the male are very small and acrocentric, that is, with the chromatids attached terminally. Using Ford's published data, we have estimated that an $\mathrm{X}$ chromosome forms about I : 35 part and the $Y$ chromosome about $1: 96$ part of the total chromosomal mass.

The growing importance of chromosomal studies is shown by the recent demonstration that alterations in the sex chromosomes, an additional $\mathrm{X}$ or lack of an X (Ford et al., I959 a and b), leads to a disturbance in the development of the gonads, the genital tracts and the secondary sex characteristics. This is the first complete linkage between genetics, cytology and human disorders.

\section{Nuclear Sex}

After mitosis, although the chromosomes merge to form the chromatin of the resting phase, their identity is not completely lost. When separated during division the $\mathrm{XX}$ chromosome pair tends to contain more heterochromatin, that is deeply staining chromatin, than the other chromosomes. This tendency was first noted and followed into the resting phase as a distinctive feature of the female in the water skater, Gerris lateralis by Geitler (Geitler, 1937). In mammals, what is believed to be the heterochromatin of the XX pair remains visible in the resting phase, as the small dense nodule described by Barr and his associates (Barr and Bertram, 1949), originally in 


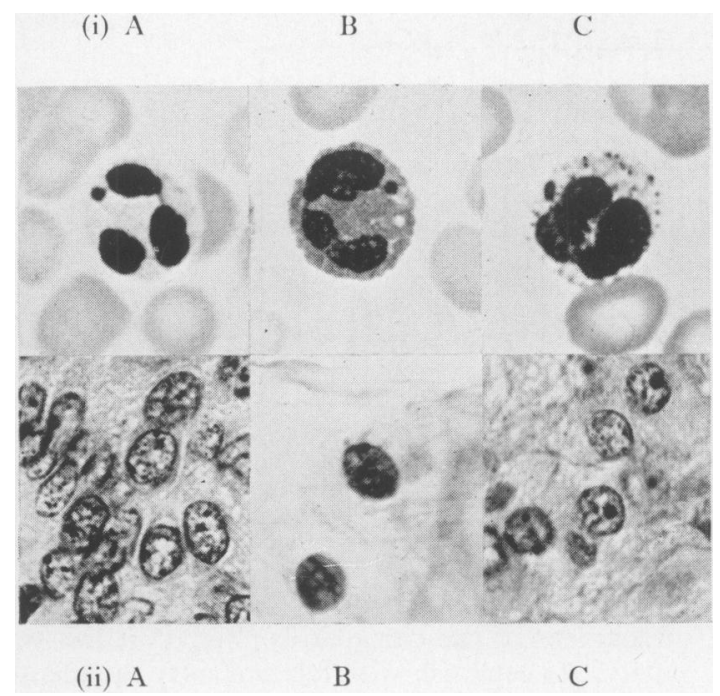

Fig. 2.-Nuclear sex in man.

(i) The characteristic drumsticks of the chromatin positive leucocytes :- (a) Neutrophil, (b) Eosinophil, (c) Basophil. Jenner-Giemsa stain. $x$ I,400.

(ii) The characteristic nodules in chromatin positive tissue nuclei:- $(a)$ Skin section, $(b)$ Buccal mucosal smear, (c) Leydig cells from the testis in the Klinefelter's syndrome. Haematoxylin and eosin stain. $x$ 930.

the nerve cells in the brain and later in other organs, including the skin (Fig. 2). In stem cells, such as those in the basal layers of the epidermis and in the marrow, this heterochromatin is not easily recognizable, but in the subsequent operational cells in the skin some 50 to 90 per cent. contain a characteristic nodule (Grumbach and Barr, 1958). In whole mounts of thin membranes it is possible to find nodules in almost 100 per cent. of the cells (Graham, 1954).

Similarly, in a proportion of the neutrophil leucocytes in female blood a sex specific heterochromatin nodule can be distinguished from other non-specific masses. In many of the neutrophils this nodule is sessile, but in about one in 38 it has a characteristic pedunculated form like a drum-stick (Davidson and Smith, 1954). This feature is not limited to human blood, where it also occurs in the eosinophil and basophil leucocytes (Fig. 2), but is also to be found in most mammals, including horses, asses, monkeys, goats, dogs, cats and rabbits (Smith and Davidson, 1954).

In the neutrophil nucleus, in Jenner Giemsa or Feulgen stained preparations, there are masses of chromatin other than the sex specific material and occasionally one may be found in either sex, which to some extent resembles a characteristic nodule. These do not occur regularly, and with experience of the method and well-stained preparations

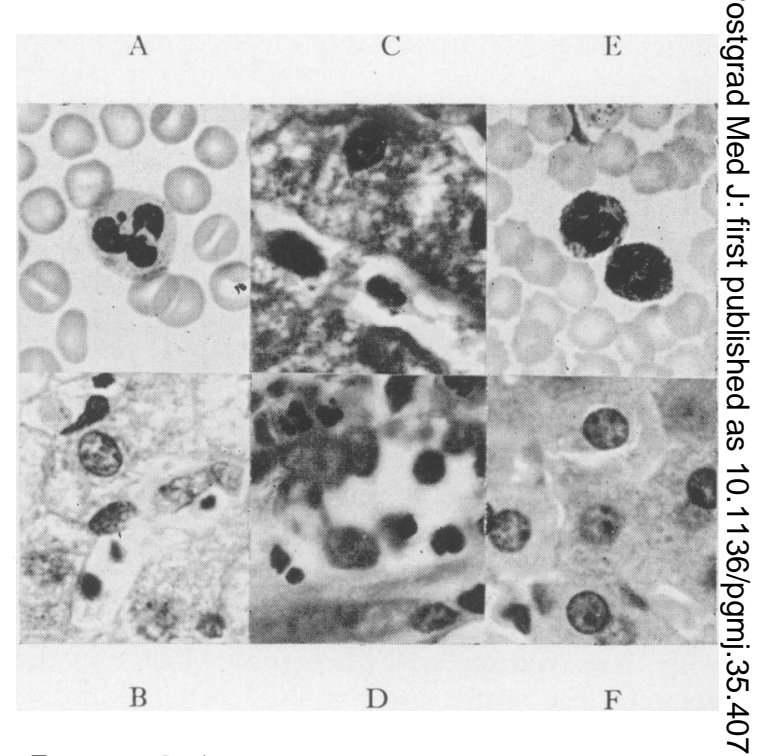

FIG. 3.-Nuclear sex in man and rabbit. The relation + ship between the size of the drumsticks in the neutrophil leucocytes and the characteristic chroe matin nodules in the nuclei of tissue cells:- thP Neutrophil drumstick in human blood (JennerGiemsa stain). (b) Nuclear nodules in hungares liver cells and (c) neutrophil drumstick from a sinusoid in the same section (Haematoxylin eosin stain). (d) Neutrophil drumstick in cap inflamed human appendix (Haematoxylin ânष eosin stain). (e) Neutrophil drumstick in raboit blood (Jenner-Giemsa stain). ( $f$ ) Nuclear nod $\mathbb{P} e s$ in rabbit liver cells (Haematoxylin and eosin stai $x 1,000$.

(Davidson et al., 1958 a) do not cause any greas difficulty. Typical sessile and pedunculate nodules never occur together in the same cello despite a suggestion to the contrary (Ashley and Jones, 1958). A smaller sessile nodule is frequently $\overrightarrow{\overrightarrow{6}}$ found in the male, but while it seems probable that it represents the heterochromatin from the single $\mathrm{X}$ chromosome it has not yet been possible. to use this criterion in the determination of sex, except as a point of limited value in the pre liminary survey of blood films.

The absence of the nodules from the nuclei of a third or more of the tissue cells is partly ex-윽 plained on technical grounds, particularly on the preservation of the cells and the frequency of the nodules is low in post-mortem material (Emery and McMillan, 1954). It is also partly due to the nature of the cells and, for example, in the epidermis the frequency depends upon the layert from which the cells have been chosen. In the same way the percentage of neutrophils containing either sessile or pedunculated nodules depends upon the quality of the preparations, but it alsoe varies from one individual to another as the resultw of factors which are not at present understood? 
The chance of finding drumsticks increases with the degree of lobing of the neutrophils (Davidson and Smith, 1958), and if it is assumed that this means with increasing age, it may be that the life span of the cells is normally too short for a high percentage to develop drumsticks. In one female with sub-acute monocytic leukaemia and a marked neutrophil shift to the right, the nodules were as frequent as one to every fifth neutrophil, while at the other extreme in the Pelger Huët anomaly, in which the neutrophil lobing is restricted, drumsticks are very rare (Davidson and Smith, I954, Lïiers, 1956).

It has been suggested that the tissue nuclear nodules and the neutrophil drumsticks are different entities on account of the difference in size recorded. The former have been estimated at close to I $\mu$ (Moore and Barr, 1954) and the latter at $1.5 \mu$ (Davidson and Smith, 1954), but in histological preparations the nodules in the tissue cell nuclei and the drumsticks found in the neutrophil leucytes in the blood vessels are of the same order of size, r.o $\mu$ (Fig. 3). Apparently spreading of the leucocytes in smear preparations increases th? measurements of the head of the drumstick very considerably. In the various animals studied the nodules were found to be of the same order of size, for example, in the rabbit blood films drumsticks were $1.2 \mu$ and the nuclear nodules in liver sections $0.8 \mu$ (Fig. 3 ).

In contrast to what one might expect, it seems that geneticists accept that the heterochromatic parts of the chromosomes are inactive and that the euchromatin, which does not stain readily, carries the active genes (Sirks, 1956). Grumbach and Barr (1958) have depicted the sex characteristic heterochromatin mass, or sex chromatin, as forming a small part, by our measurement I : 1 50, of the nucleus. Their diagram was based upon the calculations made by Moore et al. (1957), that the heterochromatin formed about I : 23 of the XX chromosomal pair. Measurements of the head of the neutrophil drumstick show that on the average this accounts for a much larger part, about $I: 34$, of the nucleus. Despite the assumptions made in the various calculations, the admitted distortion of the cells by fixation and the spreading of the neutrophils, there is still an unexplained difference between these two values.

The results of recent studies have clarified the significance of the cells being sex chromatin positive or negative. Polani et al. (1956), using colour blindness, a sex-linked recessive characteristic, as a chromosome marker suggested that cases of Turmer's syndrome, anatomical females lacking sex chromatin in their nuclei, had only one X chromosome, This has been confirmed by the chromosome studies of Ford et al. (1959 a and b) and Fraccaro and his associates (1959) and extended to show that the structure is probably $\mathrm{XO}$ and that in the Klinefelter's syndrome, anatomical males with sex chromatin nodules in their nuclei, the structure is XXY. It seems, therefore, that if the tissue cells or the neutrophil leucocytes are chromatin positive, the individual must have two X chromosomes, while conversely if the cells are chromatin negative there can only be one $\mathrm{X}$ chromosome. Thus although nuclear sexing is sufficient for the determination of the sex in normal individuals and indicates the gonadal sex in pseudo-hermaphrodites, it gives an inadequate picture of the chromosomal strusture in such conditions as Klinefelter's and Turner's syndromes. The nuclear sex determination, however, still remains a very valuable tool to the geneticist and the clinician, as its simplicity allows it to be applied widely as a screening test before any attempt is made to examine the chromosomes or conduct family studies.

It is a moot point as to whether the presence or absence of sex chromatin in the nuclei has any functional significance. It might have some bearing upon the activities of the cell, possibly in determining the response to the sex hormones, and for such a purpose intimate contact with some cytoplasmic activity could be envisaged in the peripheral situation of the nodule in the nuclei, and particularly in its projection into the cytoplasm of the neutrophil leucocytes. Against the idea of a functional significance is the fact that despite the mixture of male and female neutrophils the chimera twins, who had exchanged marrow elements across their fused placentae at an early stage of development, were in every respect normal males and females (Davidson et al., I $958 \mathrm{~b}$ ). It could equally well be argued that the sex nodule being composed of heterochromatin is inert, or nearly inert, and the drumstick formation might even be an attempt to reject the inactive material from the nucleus.

\section{Abnormalities of Sex}

Abnormalities of the genetic structure may produce apparently normally developed but sterile animals. Mules, the offspring of crossing an ass and a mare, are presumably sterile, because of some oddity in the genetic structure, yet the nuclear sex of all twelve we have studied was in agreement with their anatomical sex.

At an early stage in the development, the pattern of the genetic sex is imprinted upon the blastema of the gonad, possibly with the migration of the germinal cells. Under exceptional circumstances the gonadal sex may differ from the nuclear sex, as in the Klinefelter's and Turner's syn- 


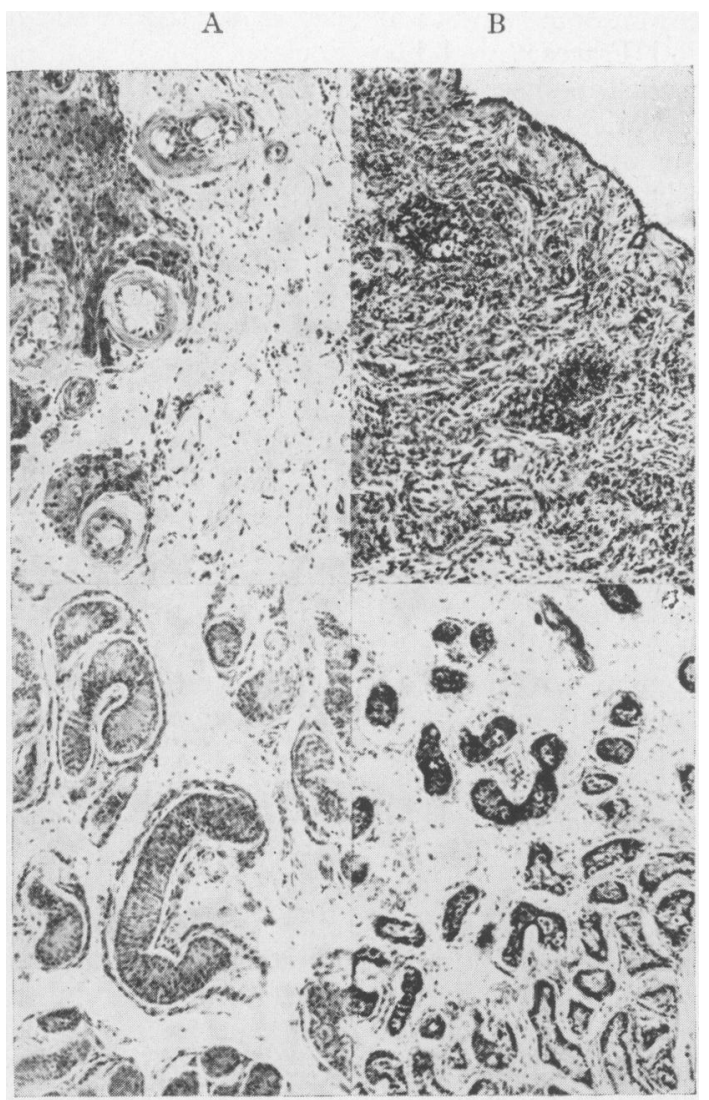

C D

FIG. 4--Gonadal sex in man. (a) The testis in Klinefelter's syndrome with hyalinization of the tubules and clumping of the Leydig cells around the less degenerate tubules. (b) The ovary in Turner's syndrome with undifferentiated tubules, containing a few germinal cells, extending in from the surface. (c) The testis in a male pseudohermaphrodite with rings of Leydig cells around the undeveloped tubules. (d) The testis in hypogonadal eunuchoidism with many germinal cells in the undeveloped tubules, but no rings of Leydig cells. Haematoxylin and eosin stain. $x 300$.

dromes. However, the divergence is not complete and in the former the testes, although they may show areas of spermatogenesis, are illformed and the characteristic picture is one of hyalinisation of the tubules and massing of the Leydig cells (Fig. 4). Similarly, the ovaries in the latter syndrome, although they may contain immature ova, are distorted and usually consist of a mass of stroma with undifferentiated tubules (Fig. 4). The recent work on the chromosomes probably explains the apparent contradiction, for the XXY chromatin in Klinefelter's syndrome is not really female and the XO structure in Turner's syndrome, or even a mosaic containing $\mathrm{XO}$, might: not react as a male.

The gonad is the operative factor in sex, supply- $\bar{z}$ ing both the germinal cells and the specific hor- $\frac{\mathbb{Q}}{2}$ mones, and even at a very early stage it directsc. the subsequent development of the genital tract. $\vec{F}$ This is apparently carried out by some local $\frac{0^{\circ}}{+}$ organiser influence, for in a true lateral herma- $\bar{c}$ phrodite the side with the testis develops along $\frac{\bar{\sigma}}{\bar{s}}$. the lines of the male, while the other side, asso-

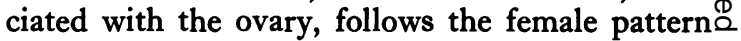
(Lindvall and Wahlgren, 1936). Abnormal testes, 为 however, may fail to produce a male genital tract. $\overrightarrow{0}$ In male pseudo-hermaphrodites, despite the chro- matin negative state of the cells and the presence $\vec{\omega}$ of testes, provided with well formed if imma- $\frac{\rho}{\circ}$ ture tubules and ample Leydig cells, the genitako tract has developed in what is essentially a female direction and sometimes so far as to produce a perfect anatomical female (Swyer, 1955). In this $\vec{\circ}$ condition the testes are probably producing a. female and not a male influence, and this is borne 0 out by the fact that castration merely makes the individual pathologically disinterested in sex (Chapple, 1937; Oldfield, 1955; and Browne, $\vec{c}$ 1955) or frankly menopausal (Bishop, 1954). A clue to the abnormality seems to lie in the curios distribution of the Leydig cells, which are pexi tubular rather than perivascular, suggesting that here they are the homologue of the theca interiag of the ovarian follicle (Fig. 4).

In the opposite condition of female pseudo hermaphroditism the gonad is an ovary and the nuclei are chromatin positive. Almost always the mal-development of the genitalia has been induced by abnormal androgens outweighing the influence $\frac{2}{\mathcal{D}}$ of the ovaries. These come from hyperplastic $\bigcirc$ foetal suprarenals or from virilizing ovarian tumours $\overrightarrow{\overrightarrow{0}}$ in the mother. Rarely the same condition has 3 been induced through the administration of testosterone to the mother (Zander and Müller, 1953) and very rarely the disturbance in development is $\frac{}{3}$ not of hormonal origin. In true hermaphrodites, for some unexplained reason the nuclei are more 3 frequently chromatin positive than chromatin negative (Davidson and Smith, 1956).

The anatomical sex depends mainly upon the vulval structure, but the secondary sex charac- $\frac{1}{3}$ teristics such as the development of a beard, the $\frac{D}{0}$ distribution of the pubic hair, the breadth of the pelvis and the size of the breasts all contribute to $N$ the differentiation between the male and female. N In addition to the general causes already dis- $N$ cussed, difficulty in determining the anatomical $\mathrm{\omega}$ sex may be due to local abnormalities, ranging from complete absence of the vulva in the sireniform anomaly (Davidson and Ross, 1954) to varying degrees of hypospadias in the male and 
A $\quad$ B $\quad$ C $D$

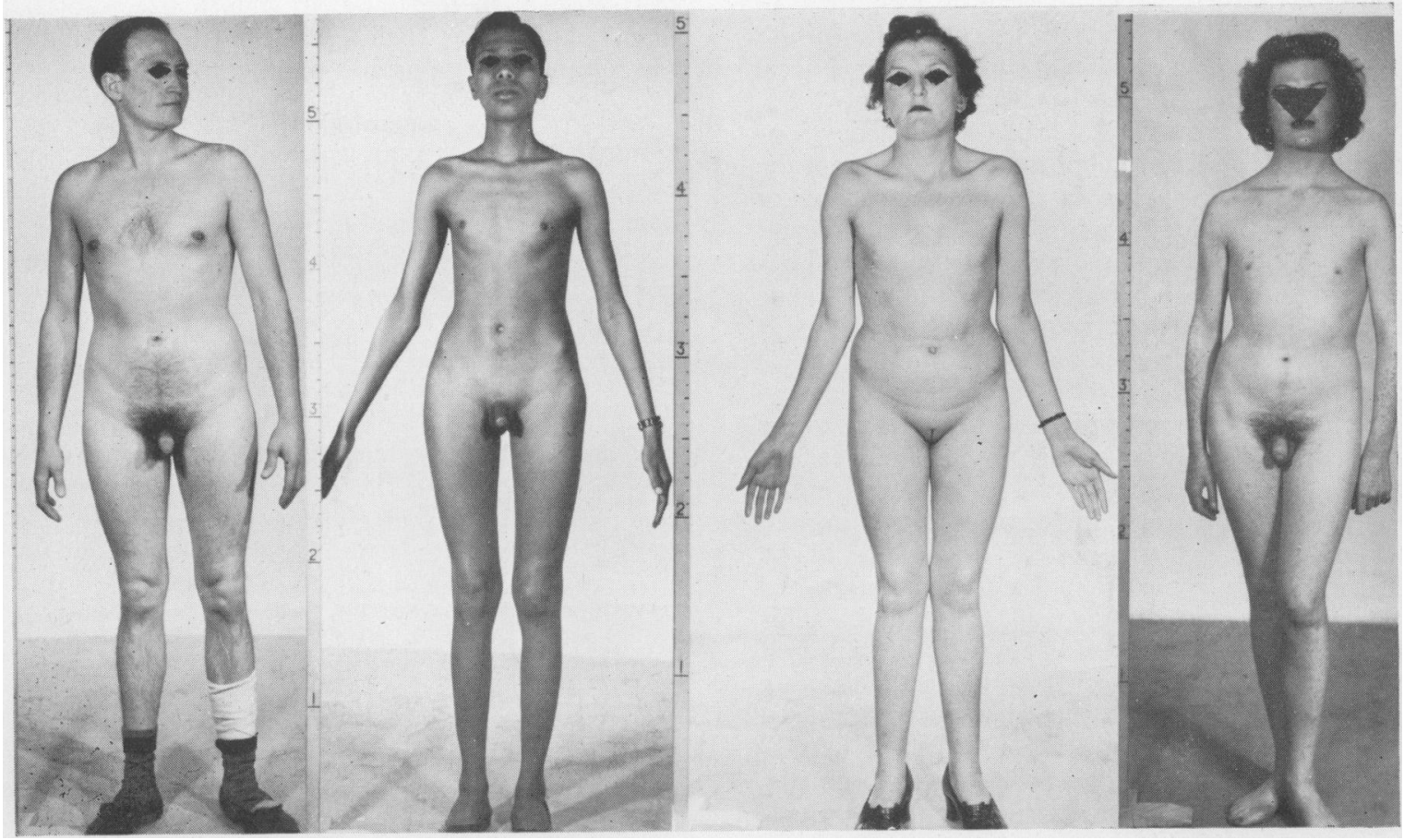

FIG. 5.-Anatomical and social sex in man. (a) Klinefelter's syndrome with hypogonadism in an otherwise normally developed male and $(b)$ in contrast the eunuchoid proportions in a chromatin negative hypogonadotrophic hypogonadism (see fig. 4d). (c) The short stature, webbed neck, wide carrying angle and lack of pubic hair in Turner's syndrome. (d) Klinefelter's syndrome with female sex behaviour.

abnormal development of the clitoris in the female. Similarly, gynecomastia may be the result of many diverse causes and hirsuitism is common in sexually active and fertile women. In these conditions, if there is any doubt, a story of the nuclear chromatin is important in deciding the sex of the individual.

\section{Social Sex}

The great influence of the anatomical sex and the sex in which a child is reared upon the psychological outlook cannot be overlooked, but there is undoubtedly a genetic background to its development. It is therefore not surprising that there may be, on occasion, psychological difficulties associated with these various disturbances of the sex organs, which are of sufficient severity to disturb the social sex of the individual. We know of at least four cases of the Klinefelter's syndrome (Bishop, I958; own; and Siebenmann, 1958) where the sexual leanings were contrary to the apparent sex, but this is the exception rather than the rule.

An individual's appearance, mental outlook, mode of dress and behaviour, determine the social sex. Mental influences appear to be the main factor in disturbances ranging from impotence and frigidity to the overt abnormalities of social behaviour such as transvestism and homosexuality. It seems that chromosomal factors play little part, certainly in transvestism and homosexuality, and the nuclear sex is not at variance with the anatomical sex in the vast majority of cases (Barr and Hobbs, I954 ; Wiedemann et al., I956 ; and Raboch and Nedoma, 1958).

\section{Summary}

The genetic, chromosomal, gonadal and anatomical development and the social outlook are expressions of sex at different levels, which are normally in harmony and produce clearly defined males and females. Under these conditions nuclear sex agrees with the other manifestations, although in essence chromatin positive and chromatin negative only indicate respectively the presence or absence of two $\mathrm{X}$ chromosomes.

The methods of determining the nuclear sex from the tissue cells and the neutrophils are 
essentially the same, and the chromatin nodules are of a similar order of size if examined in histological preparations. In cases of doubt, both blood films and sections of the skin, or buccal mucosal smears, should be examined.

Deviations at the various levels of sexual development lead to a series of abnormalities. Many of the individuals with such aberrations are incapable of marriage, others although married are sterile, and some are anti-social in their sexual outlook and behaviour. Little is known of abnormalities at the gene level. The union of genes from two different species in the mule does not affect the anatomical development, nor is it reflected in the nuclear sex, yet the animals are sufficiently abnormal to be sterile. At the chromosomal level the nuclear sex again fails to express the detail of the constitution. In the Klinefelter's syndrome, males with abnormal testes have chromatin positive nuclei, and in the Turner's syndrome, females with malformed ovaries have chromatin negative nuclei. This apparent discrepancy is explained, however, if nuclear sex is only taken to indicate the number of $\mathrm{X}$ chromosomes. In disturbances occurring at the gonadal level, producing the pseudo-hermaphrodite group of abnormalities, although the nuclear chromatin and the structure of the gonads correspond, endocrine or local influences cause a divergence of the anatomical and often with it the social sex.

Pure disturbances of social sex, unassociated with physical maldevelopment, are apparently mental disorders, and even in such reversals of social behaviour as transvestism and homosexuality the nuclear sex agrees with the gonadal and anatomical sex. The rare instances of a physical basis for a disturbance of social sex occasionally found in the Klinefelter's syndrome, and the extraordinary social position of the true hermaphrodites present problems which are difficult to resolve.

With certain limitations, nuclear sexing indicates the genetic and gonadal sex. In cases of malformation of the genitalia this is valuable in assigning the individuals to a suitable social sex, but often the anatomical sex and the mental outlook are even more important factors in making a wise decision.

We wish to thank Mr. Harland Rees, Dr. James Livingstone, Dr. Denis Hill and Dr. Samuel Oram for providing us with the cases we have used to illustrate this paper. We also wish to thank Mr.
S. H. Pegg, the senior technician in the Department of Clinical Pathology, and Mr. Smith, the hospital photographer, for their great help in producing the photomicrographs and photographs.

\section{BIBLIOGRAPHY}

ASHLEY, D. J. B., and JONES, C. H. (1958), Lancet, i, 240.

BARR, M. L., and BERTRAM, F. G. (1949), Nature (Lond.), $163,676$.

BARR, M. L., and HOBBS, G. E. (1954), Lancet, i, 1109.

BISHOP, P. M. F. (1954) ' Recent Advances in Endocrinology', 7 th edition, London, Churchill, p. 156.

BISHOP, P. M. F. (1958), 'Symposium on Nuclear Sex', London, Heinemann, p. 92.

BRIDGES, C. B. (1921), Proc. nat. Acad. Sci. (Wash.), 7, 186.

BROWNE, D. (1955), Brit. med. F., i, 1427.

CHAPPLE, H. (1937), Ibid., i, 802.

DAVIDSON, W. M., and ROSS, G. I. M. (1954), f. Path. Bact., $68,459$.

DAVIDSON, W. M., and SMITH, D. R. (1954), Brit. med. F., ii, 6 .

DAVIDSON, W. M., and SMITH, D. R. (1 956), Postgrad. med. F., $32,578$.

DAVIDSON, W. M., BAREHA.M, F. R., KITCHEN, L. D., and PEGG, S. H. (1958a), $\mathfrak{f}$. clin. Path., I1, 96.

DAVIDSON, W. M., FOWLER, J. F., and SMITH, D. R (1958b), Brit. $\mathcal{F}$. Haemat., 4, $23 \mathrm{r}$.

DAVIDSON, W. M., and SMITH, D. R. (1958), 'Symposium on Nuclear Sex ', London, Heinemann, p. 93.

EMERY, J. L., and McMILLAN, MARY (1954), F. Path. Bact., 68, 17. FORD, C. E., and HAMERTON, J. L. (1956), Nature (Lond.)
178, 1020.

FORD, C. E., JACOBS, PATRICIA A., and LAJTHA, L. (1958), Ibid., 181, 1565.

FORD, C. E., JONES, K. W., MILLER, O. J., MITTWOCH $\frac{\mathbb{D}}{0}$ URSULA, PENROSE, L. S., RIDLER, M., and SHAPIROD $\frac{\mathbb{D}}{3}$

FORD, C. E., JONES, K. W., POLANI, P. E., DE ALMEIDA J. C. C., and BRIGGS, J. H. (1959b), Ibid., i, 7 I I.

FRACCARO, M., KAIJSER, K., and LINDSTEN, J. (1959 Ibid., i, 886.

GRAHAM, MARGARET A. (1954), Nature (Lond.), 173, 310. GEITLER, L. (1937), Ztschr. Zellforsch. micro. Anat., 26, 641. GRUMBACH, M. M., and BARR, M. L. (1958), 'Recent Progress in Hormone Research ', Vol. 14, New York, Academic Press, p. 255.

JOST, A. (1947), Arch. Anat. micro. Morphol. exptl., 36, 27 r.

LINDVAlL, S., and WAHLGREN, F. (1936), Arch. path. Anat. 297, $\mathrm{I}$.

LUERS, THEA (1956), Medizin, 7, 120.

MOORE, K. L., BARR, M. L. (1954), Acta Anat., 21, 197.

MOORE, K. L., GRAHAM, MARGARET A., and BARR, M. L. (1957), F. expl. Zool., 135, 101.

OLDFIELD, M. C. (1955), Brit. med. F., i, 1338 .

PAINTER, T. S. (1 924), Amer. Naturalist, 58, 506.

POLANI, P. E., LESSOF, M. H., and BISHOP, P. M. F. (1956), Lancet, ii, 118.

RABOCH, J., and NEDOMA, KAREL (1958), Psychosom. Med. 20, 55 .

SIEBENMANN, R. E. (1958), 'Symposium on Nuclear Sex', London, Heinemann, p. 92.

SIRKS, M. J. (1956), 'General Genetics', The Hague, Nijhoff, p. 297.

SMITH, D. R., and DAVIDSON, W. M. (1954), Communication to Pathological Society.

SWYER, G. I. M. (1955), Brit. med. F., ii, 709.

TJIO, J. H., and LEVAN, A. (1956), Hereditas, 42, 1 .

WIEDEMANN, H. R., ROMATOWSKI, H., and TOLKSDORF, M. (1956), Münch. med. Wschr., 98, 1090. ZANDER, J., and MULLER, H. A. (1953), Geburts. Frauenheilk.,
13, 2 I6. 